\section{Four arrests in Californian animal-rights activism}

An international investigation has led to arrests of four animal-rights activists suspected of harassing researchers working at University of California campuses.

Agents of the Federal Bureau of Investigation seized two of the suspects on 19 February in Charlotte, North Carolina, and the other two in Oakland, California, the following day.

The four are suspects in two incidents: an alleged trespassing involving a researcher from the Berkeley campus in 2007 and a home invasion at the residence of a professor at the Santa Cruz campus in 2008. Federal authorities are continuing an investigation of firebomb attacks on homes of researchers from the Los Angeles and Santa Cruz campuses.

\section{Commercial biofuels plant planned for Florida}

London-based oil giant BP is teaming up with the biotech firm Verenium in Cambridge, Massachusetts, to build a biofuels plant in Highlands County, Florida, that will produce 136 million litres of ethanol a year from non-food crops such as grasses, the companies announced on 18 February.

The commercial-scale plant, which will begin production in 2012 , is one of the largest cellulosic-biofuel initiatives to be announced, and will cost up to US\$300 million to build. Around 8,000 hectares will be planted as feedstock.

The partners - who have each put $\$ 22.5$ million into the joint venture to date - say that they plan to build other full-scale cellulosic-biofuel facilities in the Gulf Coast region of the United States.

\section{Iran's uranium stockpile reaches weapons potential}

Iran's stock of low-enriched uranium hexafluoride would, if enriched to weaponsgrade purity, be enough for a nuclear bomb,

\section{Europa next outer-planet mission}

NASA and the European Space Agency (ESA) have chosen Jupiter's moons as the destination for their upcoming joint outer-planet flagship mission. A trip to Saturn's moon Titan may yet go ahead but needs further investigation, the agencies announced on 18 February.

The Europa Jupiter System Mission will launch two orbiters, one built by NASA and the other by ESA, in 2020, with a scheduled arrival time in the Jupiter system of 2026 The NASA orbiter will study the icy shell of Jupiter's moon Europa - which may hold an ocean capable of supporting life - and will cost US $\$ 2.5$ billion to $\$ 3$ billion, says Jim Green, director of NASA's planetary-science division.

The European part of the mission, called Laplace, will investigate Ganymede, the largest moon in the Solar System. It must still compete with two other missions to secure funding.

A longer version of this story can be found at http://tinyurl. com/bovl $2 \mathrm{j}$.

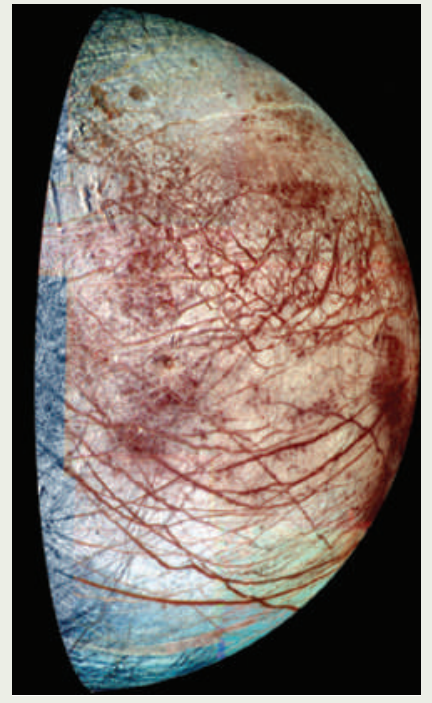

